\title{
A Special Relationship: U.S. and NATO Engagement with the Partnership for Peace to Build Partner Capacity Through Education
}

\author{
James M. Keagle*
}

A new security environment dramatically different from that which defined NATO's mission at its inception poses different challenges for collective action. Newly emerging global threats such as terrorism, cyber attacks, and the proliferation of weapons of mass destruction confront both existing Alliance members and its global partners. NATO must also consider the nature of partnership itself, and the role NATO might play in building its partners' capacity to address global threats, participate in coalition operations, and enhance defense reform.

These themes - security and partnerships - were key to the NATO Lisbon Summit (held in November 2010) and the newly crafted NATO Strategic Concept. According to the recommendations of the Group of Experts on NATO's new strategic concept, "For NATO 2020, the twin imperative is assured security for all its members and dynamic engagement beyond the treaty area to minimize threats." "Former U.S. Secretary of Defense Robert Gates identified building partner capacity as a critical element in promoting and sustaining security. In an article in the May-June 2010 issue of Foreign Affairs, Secretary Gates wrote, "[There] has not been enough attention paid to building the institutional capacity (such as defense ministries) or human capital (including leadership skills and attitudes) needed to sustain security over the long term."2

\footnotetext{
This article is a revised and updated version of one co-authored by Dr. James M. Keagle and Dr. Tiffany G. Petros and published in the 2010 Winter issue of Connections. It has been adapted for this edition of Connections by Dr. Keagle. Dr. James M. Keagle received his Ph.D. from Princeton University and served for over twenty-six years in the U.S. Air Force. A teacher for over thirty-seven years, he was provost at the National Defense University from 1999-2007. He co-leads NATO's Defense Education Enhancement Program (DEEP) efforts in Georgia (and formerly in Azerbaijan), has led DEEP efforts in Montenegro, and is the U.S. lead for Armenia. Dr. Tiffany G. Petros is currently the OSDP Desk Officer for Kazakhstan and previously a contractor supporting the Office of the Secretary of Defense (OSD) Partnership Strategy and Stability Operations. She has worked extensively in the PfP Partner countries and participated on DEEP teams in Azerbaijan, Armenia, and Montenegro. She previously served as a political science faculty member at Palacký University and the AngloAmerican College in the Czech Republic, and as a visiting professor at the American University of Armenia in Yerevan. The views expressed in this article are those of the authors and do not necessarily reflect the official policy or position of any agency of the U.S. government.

1 NATO 2020: Assured Security; Dynamic Engagement: Analysis and Recommendations of the Group of Experts on a New Strategic Concept for NATO (Brussels: NATO, 17 May 2010), 12.

2 Robert M. Gates, "Helping Others Defend Themselves: The Future of U.S. Security Assistance," Foreign Affairs (May-June 2010): 4.
} 
One way in which the United States, its NATO Allies, and Partnership for Peace (PfP) Partners are cooperating to enhance security through building defense institutions and developing human capital is in the context of professional military and civilian defense education. Many believe that education - changing mindsets and restructuring the approach to military teaching and research - and not military hardware offers the best opportunity for success.

What follows is an exploration of those innovative initiatives that NATO-both collectively and as individual members and Partner nations - is taking to support PfP members in building Partner capacity in the area of education. The central point is that these initiatives are important: from building reliable partners, to deterring conflict in Europe and Eurasia (specifically the frozen conflicts in the South Caucasus), to strengthening Partner nations from within. I will demonstrate a link between the complex security issues facing the Alliance and the role of education and training in transforming individuals, military academic institutions, and societies. Education and training transformation is a high-priority mission that will need to be sustained for decades in order to contribute to more reasoned decisions, better leadership, and ultimately a region at peace. This sustainment is critical - and will be highlighted as essential for the programs' success.

\section{NATO's Partnership for Peace}

NATO launched the Partnership for Peace in 1994 as a means of promoting reforms, increasing stability, and enhancing security relationships both between and among Partner countries and NATO. ${ }^{3}$ PfP provides a forum for Partners to individually tailor their relationships with NATO, agree on common activities, and implement them at a level and pace that is acceptable to each government. In this way, the Partners "self-differentiate" their levels of cooperation with the Alliance. ${ }^{4}$ Although several non-aligned, developed states joined PfP (e.g., Austria and Switzerland), the majority of the new PfP countries were former Communist states from the Warsaw Pact or the former Soviet Union. Thus, NATO viewed new avenues for cooperation as an important aspect of changing mindsets, such as encouraging support for democracy, as well as enhancing security through increased military interoperability.

3 There are currently twenty-two PfP members: Armenia, Austria, Azerbaijan, Belarus, Bosnia and Herzegovina, Finland, Georgia, Ireland, Kazakhstan, Kyrgyz Republic, the former Yugoslav Republic of Macedonia, Malta, Moldova, Montenegro, Russia, Serbia, Sweden, Switzerland, Tajikistan, Turkmenistan, Ukraine, and Uzbekistan.

4 Building on the success of PfP, NATO has introduced other regional partnership frameworks to enhance cooperation (e.g., the Mediterranean Dialogue to support cooperation between NATO and North African countries, and the Istanbul Cooperation Initiative to support cooperation with countries of the broader Middle East). NATO has also established the NATORussia Council, the NATO-Ukraine Commission, and the NATO-Georgia Commission to facilitate direct cooperation between these countries and the Alliance. 
Since PfP was established, twelve former members have joined the Alliance. ${ }^{5}$ NATO enlargement has replaced the traditional orientation toward containment of the Soviet Union and Russia as the Alliance's principal policy direction. ${ }^{6}$ As NATO has welcomed Allies from Central and Eastern Europe, PfP efforts and activities have been increasingly focused on countries farther to the east. At the Istanbul Summit in 2004, NATO heads of state and government agreed, "In enhancing the Euro-Atlantic Partnership, we will put special focus on engaging with our Partners in the strategically important regions of the [South] Caucasus and Central Asia.", To that end, NATO appointed a Special Representative to the South Caucasus and Central Asia as well as two NATO Liaison Officers, one to each region.

NATO's enhanced focus on Central Asia and the South Caucasus has been coupled with increased attention to education and training efforts for PfP Partners. Since 2007, NATO (and in some cases the United States bilaterally) has conducted Defense Education Enhancement Programs (DEEPs) at various levels of support and sustainment with Armenia, Azerbaijan, Georgia, Kazakhstan, Moldova, and Montenegro. The Partnership for Peace Consortium of Defense Academies and Security Studies Institutes (PfPC) has played a leading role in bringing together Allies and Partners to develop and execute DEEPs. ${ }^{8}$ These programs, which are tailored to meet individual Partner requirements, provide opportunities for the PfP states to develop both their defense education curricula and faculty. Not only do these programs provide an effective way to transform national security establishments and enhance the security capabilities of Partners, they also do so in a way that does not provoke neighboring nations. In the case of the South Caucasus, it may be the best means to avoid the region becoming a "shatter zone" along the rim land, and "marginal areas" to Mackinder's pivot and heartland thesis - a prominent line of thought in NATO as it wrestles with security challenges and opportunities in the region. ${ }^{9}$

\section{The Road to NATO Membership: The Role of NATO Tools in Enhancing Cooperation}

PfP Partners of today find themselves cooperating with a different type of NATO and using different NATO tools to tailor their cooperation with the Alliance than did early Partners turned Allies (such as the Czech Republic, Hungary, and Poland in 1999). Today's Partners fall along a spectrum. Some have expressly stated their desire for future membership in the Alliance (Georgia), while others have a desire to cooperate with

5 Former PfP Partners turned NATO Allies include Albania, Bulgaria, Croatia, Czech Republic, Estonia, Hungary, Latvia, Lithuania, Poland, Romania, Slovakia, and Slovenia.

6 See, for example, Ronald Asmus, Opening NATO's Door (New York: Columbia University Press, 2002), for a balanced discussion of NATO's enlargement efforts in the post-Cold War era.

7 NATO, "Istanbul Summit Communiqué," 28 June 2004.

8 For more information, see www.pfpconsortium.org.

9 See, for example, Robert D. Kaplan, "The Revenge of Geography," Foreign Policy (May-June 2009): 96-105. 
NATO, but also want to balance their relationship with Russia and other countries to the east (Armenia and Kazakhstan). Still other countries have changed their position with respect to NATO, given changes in their internal politics (Ukraine). NATO welcomes this diversity in its cooperative relationships, and has developed a range of tools to assist Partners in shaping the type of cooperation and activities that these nations wish to pursue.

The Individual Partnership Program (IPP) provides the foundation for cooperation between each Partner nation and NATO, and is agreed upon and renewed on a two-year basis. All PfP Partners have developed IPPs with NATO. The IPP allows the Partner to identify areas for cooperation with NATO as drawn from the Euro-Atlantic Partnership Work Plan (EAPWP). The Individual Partnership Action Plan (IPAP) goes a step beyond the IPP and is designed for Partners who are interested in an enhanced dialogue with NATO. Kazakhstan is currently the only Central Asian state to have an IPAP with NATO. Armenia, Azerbaijan, and Moldova also have IPAPs. The Membership Action Plan (MAP) is the next phase of cooperation. It is the primary tool used to prepare Partners for the responsibilities of NATO membership. Unlike IPAP, where countries identify areas that they want to address with the Alliance, MAP provides the Partner with a roadmap of NATO requirements. The Former Yugoslav Republic of Macedonia (FYROM) and Montenegro currently have MAPs. Finally, Annual National Programs (ANPs) have been established with Georgia and Ukraine to indicate a level of cooperation with NATO that is beyond that represented by an IPAP, but that proceeds on a different path from MAP.

Regardless of what path a PfP Partner chooses, the route to closer cooperation with NATO involves transforming both public and private sectors in order to promote democracy, good governance, the rule of law, and sustainable social and economic development. Beyond these goals, specific reforms of the security sector-in particular the revision of a Partner's national security plans and development of their IPAPs, MAPs, and ANPs - require that the Ministries of Defense (MoDs) understand that traditional defense functions are no longer their sole responsibility. In fact, MoD missions in the twenty-first century are just as likely to include all of the above in addition to the longstanding functions of deterring war, and fighting and winning war, should deterrence fail.

A particular challenge is how to prepare the national security professional for these new missions. No single skill set applies uniformly to the diverse set of missions in which the armed forces and individual soldiers, sailors, and airmen are likely to be engaged. Law enforcement, stability operations, peace support operations, reconstruction, and the use of deadly force are part of the landscape of these new missions. Moreover, the mission requirements of these likely actions may change when the units and individuals turn the corner, quite literally. In light of this reality, both NATO and the United States have placed education at the top of the list of transformational priorities. According to the 2010 U.S. Quadrennial Defense Review (QDR), "DOD will place special emphasis on ... building partner capacity skill sets in its professional military education 
and career development policies."10 Changing how people think, how they approach problems and analyze and evaluate courses of action, and how they implement their assignments will pose considerable challenges to the armed forces for the foreseeable future. PfP Partners also recognize the need for education and training to address a wide range of security challenges. As such, Partners from across the Balkans, Central Asia, Eurasia, and the South Caucasus have raised education and training transformation to one of the highest priorities in their agreed NATO IPAPs, MAPs, and ANPs.

\section{Building Partner Capacity: Education as a Key to Security Sector Reform}

The majority of NATO's PfP Partners are emerging from legacy systems in which decisions were made at the top and executed at the bottom, with little opportunity for discussion or input in between. Simply put, the inheritance from their pasts was one of hierarchy and centralized decision-making. Information was provided on a need-to-know basis, and interagency cooperation was not necessarily part of the decision-making process. Long-standing bureaucracies continue to shape interactions between individuals and organizations throughout much of Eurasia. However, in order to meet today's challenges, there is a greater demand for effective integration of all instruments of powermilitary, political, economic, and informational - by multiple agencies of the security establishment rather than the singular application of a particular instrument of power by a single organization. This is true not only for PfP Partners, but also for the United States and other NATO Allies, all of whom struggle with how to make the interagency process more effective, transparent, and useful. Moreover, flatter and more decentralized organizational approaches populated by soldiers, sailors, and airmen who are adaptable, flexible, and capable of creative and critical thinking are prerequisites for the national security establishments of the twenty-first century.

Even though almost all the results that national governments strive to achieve require the concerted and coordinated efforts of multiple agencies, linear thinking and parochialism can still dominate. Blaming others is more common than accepting shared responsibility and sharing resources. Worse, few incentives exist to collaborate. In fact, barriers to and punishment for such sharing and collaboration are more often the norm.

What is needed is a means to break down these closed, hierarchical, self-interested, and stove-piped systems in favor of systems and processes that can transcend organizational and personal boundaries to achieve effective cooperation. Such a philosophy rests upon the following principles:

- Few organizations can successfully provide all the required resources, authority, and expertise on their own

- Matrixed, networked organizations are the goal

- Cultural change should precede systemic reform

- Changing people (and the way they think) is the key to changing organizations.

10 U.S. Department of Defense Quadrennial Defense Review (Washington, D.C.: U.S. Department of Defense, 12 February 2010), 54. 
This new paradigm first and foremost demands an investment in education, in changing the way people think. Most importantly, that entails new curricula, different faculty and student bodies, and teaching methodologies based on active learning in order to expand the next generation of leaders' peripheral vision. Equally important, there needs to be a transformation in the academic setting, with a classroom experience that replicates the interactions that will take place in the new security environment. That means that classrooms should include different types of students - with diverse personal and organizational perspectives, drawn from a pool representing the entire national security establishment - army, navy, air force; ministries of defense, foreign affairs, commerce, interior, justice, etc.- and our Allies and coalition partners. These kinds of student bodies will enrich dialogue and discussion, all while encouraging the critical thinking that is so essential to addressing the challenges of today. Simply put, the classroom has to transform from a lecture-centric environment to multiple active learning experiences with significant student interaction and the teacher acting as a facilitator just as much as a transmitter of facts.

\section{The New National Security Professional}

As NATO Allies and PfP Partners work together to build defense institutions and develop human capital, programs need to be put in place to educate national security professionals in new ways and produce graduates with different skill sets. They need to be able to:

- Think strategically (not just operationally or tactically), critically, and creatively

- Lead interagency teams

- Collaborate and persuade, not just "command"

- Plan and manage interagency operations

- Possess global and cultural acuity

- Communicate (not just issue orders).

The aim is to develop national security professionals who, in the dimensions below, shift their intellectual balances in the direction of the left-side characteristics (see the table below).

This is the domain of education and training. It is what is motivating NATO to shift its attention from weapons systems to joint, multinational, and interagency education and training of those people who more broadly develop and employ the doctrines, strategies, and policies that integrate all the instruments of power-political, military, economic, and informational - to produce leaders better equipped to deal with a range of issues that define the twenty-first century security environment: "smart power." formation and miscalculation can lead to poor leadership and decision making — and to

11 See U.S. Secretary of State Hillary Clinton, testimony to the U.S. Senate Appropriations Committee, Washington, D.C., 30 April 2009. 


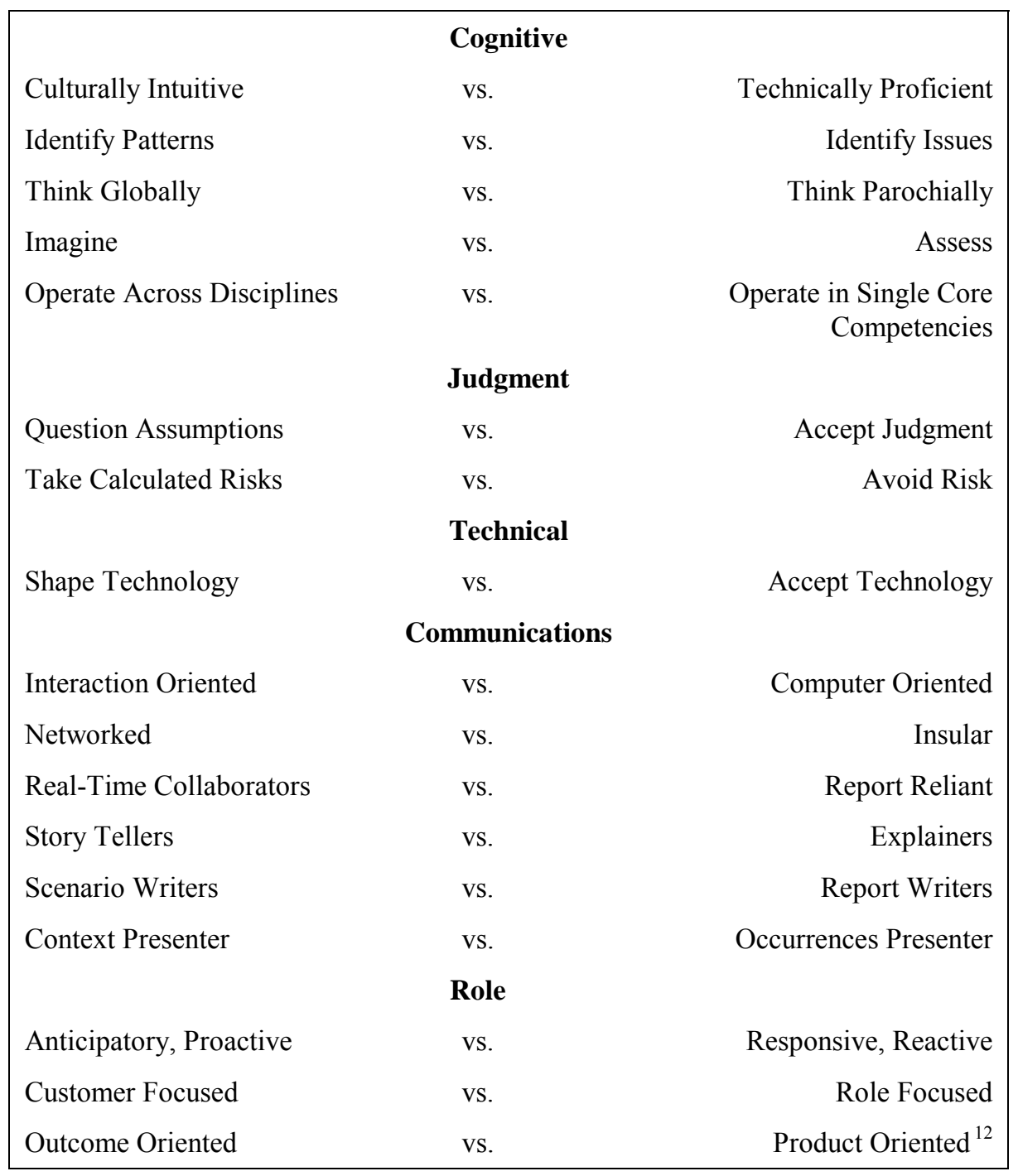

war, death, and destruction. Limiting those outcomes is what national security education and training transformation is all about. It will require different kinds of faculty, different kinds of curricula, and different approaches to teaching. Moreover, it will require patience, for none of these transformations will occur overnight.

12 Information formally presented by Ms. Platz-Vieno in a PowerPoint brief at the National Defense University (NDU) on 23 February 2009. 


\section{The NATO Response: The Process Operationalized}

As developing PfP Partners look to better understand Western "ways of thinking and educating" and develop their own national security professionals, they have turned to NATO Allies and other Partners for support in developing professional military education (PME). Countries from the Balkans, Central Asia, South Caucasus, and Eurasia are all engaged in discussions with NATO on PME topics of interest through both bilateral and multilateral DEEPs. ${ }^{13}$ PfPC has played a particularly important role in facilitating this engagement. The DEEP approach, as described below, provides an alternative to sending Partner officers, NCOs, and civilians to courses abroad, and thus makes defense education more accessible to a larger number of participants. Since DEEPs are tailored to meet individual Partner needs, they also provide PfP members with the opportunity to self-differentiate in both their assistance requests and in the level of cooperation they desire with NATO on PME issues. DEEP initiatives to date have responded to a variety of requests for assistance, including developing course modules, establishing a command and general staff college, starting up research institutions, and offering faculty "shadow" programs, to name a few.

In order to establish a DEEP between a Partner and NATO (or an individual ally nation, if the DEEP is bilateral), NATO (or the ally) sends a visiting team of subject matter experts to the Partner country for approximately one week to discuss Partner needs, priorities, and objectives for future education reform. These Curriculum and Teaching Development Teams (CTDTs), made up of three to five persons, are composed of subject matter experts who are academics (teachers) and practitioners with recent field experience, as well as those who are knowledgeable on the countries and their sensitivities. On their side, the Partner country identifies future instructors, heads of existing military institutes/training departments, and others involved in education reform who will be instrumental to the change process. The Partner state also provides opportunities to meet with political and military leadership in order to ensure that support for education reform is gained and maintained at the highest levels. By including education and training as a priority in their NATO documents (IPAP, ANP, or MAP), the Partner state also signals to NATO the importance it is placing on reform in this functional area.

Once a baseline is set and an Action Plan has been agreed upon between NATO and the Partner (or bilaterally), the CTDT makes repeat visits to the country to assist with both curriculum and faculty development as needed. In some cases, this means that the

13 The DEEP initiative began in 2007 with a program in Kazakhstan (with NATO and U.S. coleads) and has since expanded to include countries in the South Caucasus and Balkans region. Current DEEP programs include Afghanistan (NATO lead); Armenia (NATO and Canadian coleads); Azerbaijan (NATO and U.S. co-leads); Georgia (NATO and U.S. co-leads); Moldova (NATO and U.S. co-leads); and Montenegro (U.S. lead). It is important to note that other Allies and Partners are contributing both to the DEEP teams and to a range of other PME activities to support PfP Partners that are outside the scope of the DEEP projects. Efforts are being made to de-conflict all relevant projects while providing the Partners with necessary subject matter expertise. 
team co-teaches courses for a couple of days with the host-nation instructor to provide a practical component to the theoretical discussions on methodology, syllabus development, etc. Over time, the CTDT recedes to the background while the host nation assumes the primary role. The CTDT remains ready to assist or provide additional information on an as-needed basis.

The key to this is sustainment - of the effort and the people involved, by both NATO and the host nations. Without such continuity it is unlikely that we would be able to engage in the frank and open exchanges so necessary to introduce such dramatic changes in individuals, education and training institutions, and societies. NATO has been fortunate to provide such stability through the leadership exercised by Mr. Jean d'Andurain in the International Staff and his individual country academic co-leads. Obtaining the same continuity from the recipient nations has proved more problematic, and has slowed progress.

\section{Implementation}

Depending on a country's needs and the availability of Allies and NATO to support program implementation, the CTDT visits may be conducted on a multinational or bilateral basis. A NATO representative may also be involved in crafting the Action Plan (in accordance with other NATO agreements, such as IPAPs) and/or the NATO Liaison Officer (LO) in the region (in the case of the South Caucasus and Central Asia) may play a role. The NATO LO may be active in crafting the plan, assembling the CTDT, and consulting with the Partner between visits to ensure that the process is moving forward as scheduled. To ensure support from all sides, the DEEP PME action plans were historically briefed at NATO Headquarters in the Political and Partnerships Committee (PPC; formerly the Political-Military Steering Committee), although this practice no longer continues. One critical lesson learned is that any success depends on support from the U.S. country team and the NATO regional liaison office. Such success is hampered should either find a DEEP to be redundant or potentially in conflict with other national or Alliance programs.

Shadow faculty visits deserve particular mention. A number of Partner counties have conducted such visits, both in the U.S. and Europe, offering a select number of newly identified faculty the opportunity to see firsthand not only how NATO and the U.S. approach classroom education, but also to get a behind-the-scenes set of observations regarding curriculum development and faculty preparation. These are an invaluable set of experiences for faculty in transitional nations.

\section{Review and Assessment Session}

At the beginning of each new year of the DEEP, and following the approval of an action plan, a select team of NATO experts (normally Mr. d'Andurain and the academic colead) and their counterparts from the Partner nation's MoD should conduct a review and assessment. The objectives of this session are to assess the effectiveness of the program and complete the coordination for the events scheduled for the upcoming year and beyond. The pace and intensity of this action plan can be adjusted to reflect the needs of 
the host nation. Priorities should be reaffirmed and additional requirements should be identified.

\section{End State}

The desired end state of these PME action plans is to meet the educational objectives of the host nation as specified in their Membership Action Plan, Annual National Program, or Individual Partnership Action Plan. As such, they are focused on institutional enhancements, curriculum development, adoption of NATO standards, and faculty development and education. Implementation of this action plan should result in the establishment of a professional military education program that will prepare officers and NCOs for complex and interagency operations and that enhances intellectual interoperability between NATO and PfP Partners. Executing the events suggested in this plan will also contribute to strengthening the cooperative relationship between NATO and the host nation.

Although existing education programs between NATO and PfP Partners primarily focus on professional military education, a recognized need exists for professional education for civilian defense officials as well. Many PfP Partners are just now introducing civilian employees into their MoDs and beginning to work with think tanks and institutes that rely on civilian defense expertise. The education of civilians will thus take on an ever more important role in developing national security professionals and reinforcing the principle of civilian control of the uniformed military.

In addition to educating civilians, the DEEP initiatives seek to work with PfP Partners to consider how to make more effective use of their existing civilian universities to support the development of military and civilian defense officials. Programs at civilian universities - including politics, humanities, finance, etc.-have relevance to defense curricula, and could play an important role in supporting defense education. Hand-inhand with this is collaborative research with civilian universities and the private sector, as well as the importance of viewing each as a potential source for faculty. This is an area that can and should be developed more in the future.

\section{Curricular Challenges}

As NATO and Partner nations work together to rethink their defense curricula and make changes that will increase intellectual interoperability, a number of areas must be considered. This is particularly true since curricula intersect and interact with several other aspects of a country's military system, from strategy and doctrine to the development and implementation of human resource management systems to how lessons learned from military operations are captured and integrated to ensure continuously enhanced preparation and improved execution.

In order to better understand the role education plays in the larger military framework and the various aspects of curricula that need to be considered, the following areas should be highlighted: 
- Doctrine and defense planning education and training. Doctrine is at the core of any national security establishment, and how to incorporate its fundamental principles into the education and training system is a requirement of the first order. It is the central document that guides force structure and its management. From that will flow all serious programs in defense planning, be they based on SWOT (strengths, weaknesses, opportunities, threats) analysis; courses of action analysis; ends, ways, and means analysis; or other models. While often understood as strategic in nature, education and training programs in doctrine and defense planning need to be melded into curricula at the tactical and operational levels as well. All involved in this process must understand a critical tension that exists between rehearsed behaviors based on doctrine, tactics, techniques, and procedures on the one hand and the adaptive and flexible behavior stressed in critical thinking on the other hand.

- Personnel management system integrated with professional military education and training and force management. It is essential that a personnel management system be married to the education and training transformation efforts. This is all about ensuring that the right individuals get the right education and training at the right times in their careers. This means careful coordination of pre- and post-education assignments, rigorous processes for student selection, and proper attention to promotions for both faculty and students. Both student and faculty assignments must be perceived as career-rewarding, not careerthreatening or career-ending. The legislative branch may be required to actively oversee these personnel functions to ensure that operational pressures do not override the need to invest in education and sustain that investment over the long term. The NATO-U.S. partnership has worked together to ensure that parallel and supporting efforts in education and personnel management coexist in each country. These have been in practice a combination of NATO and national programs.

- Cradle-to-grave curriculum review and transformation throughout the education and training system. Specific emphasis within the curriculum review process needs to be placed on the operational and strategic levels; tactical-level emphasis, while important, needs to be balanced with education and training at the operational and strategic levels. This is all about priorities - and the host nation must be given latitude in determining entry points to effect change throughout the system. Our experience suggests that the operational level may be the best place to begin. Specific areas of interest seem to be: command and control, integration of the air-land battle, air defense support, and logistics/supply chain management. Education early in one's career should be focused on developing specific core competencies and is most likely principally conducted in a service-specific or organization-specific environment. Over time, the individual needs to be educated in a more balanced joint, multinational, and interagency academic setting. Pure arithmetic suggests that strategic-level education (war colleges), while it may be desired as a source of national pride, is far more dif- 
ficult to justify economically. This is one of many areas that may be suited to cooperative regional efforts, particularly among smaller partner countries, which have initially concentrated on intermediate-level and operationally-focused command and staff courses.

- NCO education. Special attention needs to be paid to the non-commissioned officer (NCO) corps. Increasingly, the leadership and decision-making roles of the NCO are crucial to success on the battlefield. For several PfP Partners, developing and changing the manner in which NCOs are utilized will be particularly important to the transformation of their armed forces. While many different approaches to NCO education and training exist in NATO, they all share one common feature: each recognizes the value of NCOs in the leadership and management of the force, and educates and trains the NCOs to perform these leadership and management functions. The PfP Consortium's decision to create a reference curriculum for NCO education (due to be published in mid-2013) highlights the importance of the NCO's role.

- Pre-commissioning programs. It is essential to invest early in the development of the next generation of leaders. While four-year education models may not be an affordable answer either in time or money for every country, certainly multiyear programs are an appropriate model that can provide the intellectual foundations upon which to build the future security leadership. Investing early to build solid foundations will yield significant benefits over the course of one's career. Again, the costs need to be balanced against considerations of national pride and unity that having one's own "West Point" may yield.

- Junior officer education. Continuing with the theme above, early investment in military education systems for lieutenants is paramount to develop the core competencies necessary for tactical, operational, and strategic-level joint, combined, and interagency missions. Time is the critical variable, and each country is under different kinds of pressure to shrink the investment in education and get their new crop of officers into the field. These impulses need to be balanced against the need to educate and train their officers more fully, so that they understand their core competencies and can represent them effectively in the security environments in which they are likely to operate.

- Mid-level officer education. Mid-level education for senior captains and majors is the place to truly emphasize the shift from service-specific core competencies to the joint environment. Multi-service operations are increasingly the norm. Education that mixes a curriculum specializing in joint operational content with a joint classroom environment will build the kinds of expertise, institutional understanding, and personal levels of trust to produce more effective security strategies and problem solving.

- Senior officer education. Focused on war studies, decision making, defense management, rule of law, ethics, the geo-political context, and leadership, PfP countries need to consider, as resources permit, senior leadership courses up to 
one year long for their lieutenant colonels and colonels. As valuable as they are in the field, it is even more important now to create the appropriate academic environments for senior officials so that they can test their ideas and expand their peripheral vision in concert with those with whom they will likely interact in their next assignments.

- General officer education. At the general officer level, the emphasis truly shifts to leadership and decision making, likely to be conducted in partnership with senior civilian defense officials and in coalition and interagency environments. Courses of several weeks up to two months long are the appropriate length to consider. In nearly all cases Partners will have to rely on courses abroad for the near and mid-terms.

\section{Faculty Challenges}

Like curriculum development, faculty development is key to transforming PME systems in PfP Partner countries. The development of human capital is crucial to the success of individual Partner PME action plans, and more importantly to the ability to sustain transformation. Some key faculty challenges are as follows:

- Develop teaching skills for existing and new curricula, as well as processes for curriculum development, review, and refinement. This may be the single most important — and difficult — challenge faced by educators. A novel approach that has emerged as part of DEEP initiatives is a "shadow faculty" program, as was mentioned above. The U.S. Naval War College became the first host of such a program in 2011. The idea here is that Partner nations send select faculty to a U.S. military education institution for several weeks, to live first-hand the life of a faculty member, e.g., participating in faculty meetings where colleagues discuss curricula, methodologies, and individual approaches to lessons; in actual seminars; and in post-seminar and course reviews, among other activities. This has been followed in the U.S. with similar programs at Ft. Leavenworth and the Joint Forces Staff College.

- Establish a personnel management system that provides incentives for faculty duty. Essential to meeting this challenge is building and maintaining a faculty that has the right balance of academic credentials, teaching expertise, and operational experience. This includes keeping long-serving faculty current through operational and academic sabbaticals and having faculty duty be viewed as career-enhancing, with the proper promotional and assignment opportunities for those faculty who depart after a tour of faculty duty. This commitment to a core faculty (who would ideally be present for at least three to five years) is essential to the stability needed to oversee education transformation.

- Establish an MoD program for the recruitment, training, and professional development of $M o D$ civil servants. The growth and nurturing of a civilian cadre of defense officials is an urgent need for all the countries of the region. 


\section{Student Body Size and Composition Challenges}

The selection of students and the ability to retain students after graduation is key to the success of PME reform in PfP countries. Below are some issues to consider in selecting students and determining student body composition:

- Develop a rigorous and open process based on merit for the selection of the students to attend various PME programs. Ensure proper assignments and utilization for students upon graduation. This reinforces the concept of the right education for the right student at the right point in his/her career.

- Balance formal academic programs with other social and athletic elements to build trust and relationships between the students. These extracurricular activities can also help bond the PME institution with the local community, and the nation.

- Create sufficient time outside of the formal classroom activities for critical thinking and reflection.

- $\quad$ Construct adequate educational facilities, including billeting.

\section{Summary and Conclusions}

Education and training transformation across the Partnership for Peace countries is intended to contribute to peace and security in the Euro-Atlantic region and beyond. It may ultimately prove to be key to strengthening defense institutions, enhancing capabilities to support coalition operations and respond to global threats, and possibly even unfreezing existing regional conflicts. In addition, it will help to develop adaptable and flexible individuals with new ways of thinking, a willingness to work across agencies to improve decision making, and an interest in supporting reforms and training a new cadre of defense professionals to do the same.

The willingness of PfP states to undertake a DEEP as an innovative approach to defense education reform is an important first step. It is understood by NATO that reforms will not always be quick or easy. However, by working with the Alliance, Partner nations can benefit from a range of perspectives and subject matter expertise that may not be otherwise available to them. For example, DEEP initiatives offer PfP nations the opportunity to hear from former Partners turned Allies regarding the lessons they have learned. Romania, Poland, Hungary, and the Czech Republic have played important roles on DEEP teams by offering to share their recent experiences. For example, as a PfP participant, Romania received the support of a Curriculum and Teaching Development Team (CTDT) in the area of defense resource management and subsequently developed a program that later expanded to include Partners in South East Europe. These success stories demonstrate that small steps and committed individuals can ultimately bring about big change.

Finally, the priority NATO has placed on the topic of professional and civilian military education can also be seen through its commitment to the development of reference curricula to be shared with Partners. A Partnership Action Plan on Defense Institution 
Building (PAP-DIB) Reference Curriculum and a Generic PME Curriculum have already been published. These publications offer a resource to those who are working to develop programs consistent with Western standards. NATO has also stressed the value of using Western learning methods based on active learning models, student-centered versus teacher-centered instruction, and critical thinking to boost absorption of curriculum content. Partners are increasingly adopting these methods. PfP nations and current Allies should use all of the resources available to them to build Partner capacity and enhance human capital. It is through our shared contributions and collective action that we will meet the new challenges of the twenty-first century. Building a self-sustaining educational foundation, not just operational capacity, may be the critical cornerstone to building lasting security policies - and enduring peace. 
THE QUARTERLY JOURNAL

\section{Bibliography}

Asmus, Ronald. Opening NATO's Door. New York: Columbia University Press, 2002.

Clinton, Hillary. Testimony to the U.S. Senate Appropriations Committee. Washington, D.C., 2009.

Gates, Robert M. "Helping Others Defend Themselves: The Future of U.S. Security Assistance." Foreign Affairs (2010).

Kaplan, Robert D. "The Revenge of Geography." Foreign Policy (2009): 96-105. 